\title{
Einstein e a Relatividade entram em cena: diálogos sobre o teatro na escola
} e um ensino de Física criativo ${ }^{+*}$

\author{
Letícia Maria Oliveira ${ }^{1}$ \\ Universidade Federal do Vale do São Francisco \\ Senhor do Bonfim - BA \\ Maria Letícia Alves Gomes ${ }^{2}$ \\ E. E. F. M. José Matias Sampaio \\ Brejo Santo - CE
}

\section{Resumo}

Nesse trabalho, buscou-se inovar a maneira de apresentar a Física aos alunos, incluindo nessa inovação: como ela aconteceu, o que proporcionou e a forma de apresentá-la aos leitores. Para tanto foi escolhido o teatro, sob a ótica do qual o conhecimento científico pode ser representado sem o rigor que o engessa, ao mesmo tempo em que a arte de encenar contagia e provoca reflexões no ator e no espectador. O produto gerado a partir desse trabalho foi a formação de um grupo de teatro científico em uma escola de Brejo Santo, no interior do Ceará, com a encenação de peças teatrais e a elaboração de um site. Os personagens "Ensino Tradicional" e "Física Nova" são os protagonistas dessa história e nos mostrarão em seus diálogos, como é difícil, porém possível, semear nas escolas, possibilidades de um ensino atrativo e divertido. Entre os resultados, foram percebidas positivas mudanças no grupo, como a postura do aluno em sala de aula, além de receptividade e respeito entre os colegas e com o professor. Além de começarem a enxergar a Física de outra maneira, deixando-os mais motivados a aprender essa ciência. Nesse sentido, diante do quadro atual da educação brasileira, o objetivo do trabalho concentrou-se na necessidade do docente atuar de forma diferenciada, atra-

\footnotetext{
${ }^{+}$Einstein and relativity takes the stage: dialogue on the theater in school and a creative Physics education

* Recebido: maio de 2016. Aceito: agosto de 2016.

${ }^{1}$ E-mail: leticia.maria@univasf.edu.br

2 E-mail: m213a4g5@gmail.com
} 
vés de estratégias e novas metodologias. Logo, a prática teatral, mais especificamente, o teatro científico, pode ser uma ferramenta de grande potencial didático na prática didático-pedagógica dos professores, contribuindo, assim, no processo de ensino e aprendizagem de Física.

Palavras-chave: Teatro Científico; Ensino de Física; Relatividade.

\begin{abstract}
In this work, a creative way to teach Physics to the students in Regular Education is suggested, by presenting the following aspects: how it happened, outcomes, and the way to present it to the readers. The theater was chosen, considering that scientific knowledge can be represented beyond its rigidity, at the same time that art provokes reflections in the actor and in the spectator. A group of scientific theater was created in a school in Brejo Santo, Ceará, and besides staging, a website was elaborated. The characters "Traditional Teaching" and "New Physics" are the protagonists of the story and they will show us in their dialogues, how difficult it is, however possible, to show possibilities of Physics teaching through an entertaining approach in regular schools. Among the results, positive changes were noticed in the group, as the student's posture in classroom, besides receptivity and respect among the friends and with the teacher. Besides, they began to see Physics in another way, becoming more motivated to learn this science. In that sense, considering the current brazilian education, the objective of this work focuses on the teacher's need to act in a differentiated way, through strategies and new methodologies. Therefore, the theatrical practice, more specifically, the scientific theater, can be a tool of great didactic potential in teachers' practice, contributing for teaching process and learning of Physics.
\end{abstract}

Keywords: Scientific Theater; Physics Teaching; Relativity.

\title{
I. Introdução
}

Não se pode negar: existe um ensino tradicional ao mesmo tempo tão presente e tão distante da realidade do aluno, que há muitos anos predomina nas salas de aula e que, contudo, tem colaborado cada vez menos para o desenvolvimento de um ensino de qualidade. Tão presente porque ele está todos os dias na sala de aula; e tão distante, porque não mostra aos alunos, quão próximos de suas vidas estão todos aqueles conteúdos que lhes são apresentados de modo entediante. 
A Física é uma das estrelas que compõem o belo espetáculo no ensino e aprendizagem do jovem, por isso requer uma nova configuração de abordagem em sala de aula: para que se torne aliada, e não inimiga, no processo de aprendizagem.

Segundo Mizukami (1986), o professor deve colaborar nas formas do aluno aprender significativamente, ampliando ou modificando suas estruturas, provocando conflitos cognitivos, desequilíbrio, a partir dos quais, mediante atividades, o aluno consiga reequilibrarse, superando a discordância e reconstruindo o conhecimento.

A autora sinaliza que atividades colaborativas com o aluno, possibilita a construção da aprendizagem e do conhecimento, pois explorando as habilidades de cada um, pode-se observar e modelar as contribuições que todos podem dar. Dessa forma, o jovem atuando na apropriação e construção do conhecimento científico, terá maiores condições de interagir com a Física e relacioná-la com a sociedade.

Alguns autores (FERREIRA, 2004; OLIVEIRA; ZANETIC, 2004) apontam a prática teatral como um meio possível na busca do conhecimento com alegria, ou seja, ele permite que o momento de aprender seja um momento de satisfação, onde a sala de aula se transforma num ambiente agradável e participativo. Segundo estes autores, a atividade teatral, ao trabalhar a sensibilidade, a percepção, a intuição, as emoções, pode permitir ao aluno fazer relações entre ciência e questões sociais, como também proporcionar a coragem para se arriscar, descobrir e anunciar a sua crítica, expor sua forma diferente de pensar (OLIVEIRA; ZANETIC, 2004).

Diante disso, surge a necessidade de inovar as práticas, buscando novas metodologias e estratégias que despertem no aluno competências específicas em Física, levando-o a interagir com competências de outras áreas de forma a se apropriar de um aprendizado mais amplo e interdisciplinar. Além de instigá-lo a pensar a Física de outras maneiras, procurando mantê-lo interessado na disciplina.

Nesse presente trabalho, o que se intentou foi gerar um produto que extrapolasse os limites das salas de aula, chegando aos palcos, às páginas da internet, e ainda não satisfeito, também se fazer presente nas páginas da dissertação, do produto, e por que não no artigo através do qual esse trabalho será divulgado.

Ao se decidir sobre o tema do produto, fruto dessa dissertação de mestrado, e tendo, pois, optado pelo uso do teatro no ensino da Física, estava lançado o desafio: fazer do teatro uma forma de gostar da Física. Frente ao ensino tradicional, com seu domínio e resistência, e frente ao sistema educacional falido e fadado à descrença, fez-se a perguntar: por que não fazer diferente? Não apenas reproduzir, mas inventar, chamar os meninos a pensar a Física, a conhecê-la por meio de sua história e beleza? Ao responder a essa pergunta, também se lançou o desafio.

Nessa e por essa tentativa, por que não contar a história da Física? Por que não estimular os jovens a criarem a partir dessas histórias; das histórias de descobertas, de anseios e verdades reviradas vividas pelos físicos, principalmente pelos que viveram o início do século XX, como nosso tão conhecido Albert Einstein? Por que não falar de Einstein e da relatividade 
aos jovens do Ensino Médio, fazendo-os perceber a curiosidade e a grandiosidade da Teoria da Relatividade Restrita? E depois disso tudo, por que não sugerir que criem uma peça e a encene, sem grandes pretensões, apenas considerando uma nova forma de falar de Física?

No ensino, infelizmente e predominantemente, todo conhecimento é dito e repetido sem que se pense sobre ele, tampouco que a partir dele se crie. A isso se intitula "ensino tradicional", embora essa denominação tenha uma descrição que vai muito além de uma prática negativa. $\mathrm{O}$ "ensino tradicional" não é um vilão, dentro dele muito se pode transformar, mas como dito, frente à resistência tradicionalista, o novo ensino, uma nova forma de falar de Física, terá de ser também bastante resistente, persistente, além de muito convincente.

Vamos então conhecer e acompanhar essa história, inspirada e baseada na dissertação de mestrado "Einstein e a Relatividade entram em cena", da aluna Maria Letícia Alves Gomes, concebida por meio do Mestrado Nacional Profissional em Ensino de Física.

\section{Sobre a inovação do Ensino de Física}

[As aulas recomeçaram. Física Nova e Ensino Tradicional encontram-se e debatem sobre as reais e verdadeiras inovações do Ensino de Física.]

FÍSICA NOVA: Quais são as novidades, Ensino Tradicional, nesse início de ano para nossos alunos?

ENSINO TRADICIONAL: Ah, temos muitas novidades. A escola foi reformada. Temos agora azulejo nas paredes, portas e ventiladores novos, e o professor pode agora escolher entre giz e pincel. Os banheiros também estão novinhos.

FÍSICA NOVA: De fato, a estrutura física melhorou bastante!

ENSINO TRADICIONAL: Ah, e computadores novinhos...

FÍSICA NOVA: Hum, que bom... E para motivar os alunos a tomarem mais gosto pela Física, o que temos de novo?

ENSINO TRADICIONAL: Você acha isso pouco?

FÍSICA NOVA: Não é isso, Ensino Tradicional. Escola arrumada e computadores novos são apenas detalhes. É preciso "mais" para que o aluno se interesse e aprenda de verdade. Certa vez, Ensino Tradicional, eu vi uma cena que muito me entristeceu e preocupou, e há sua presença nela, de certa forma.

ENSINO TRADICIONAL: Sou sempre o culpado pelo desinteresse dos alunos.

FÍSICA NOVA: Não, não apenas você. Mas me deixe contar a história:

O sino toca. É o fim do recreio, mas os alunos continuam alvoroçados do lado de fora. Alguém pergunta:

- De que é essa aula? 
- Física!

- Aula chata! O professor enche o quadro com um monte de fórmulas e cálculos que eu não sei pra que servem.

- Também, a gente passa a aula conversando.

- Claro! O problema é que as aulas são sempre as mesmas!

- É igual a médico que receita o mesmo remédio...

- Paracetamol!

(Todos caem na gargalhada).

- Vamos lá para a quadra?

- Só se for agora!

FÍSICA NOVA: Nós, professores, ficamos angustiados ao ver esse tipo de cena. Realmente, temos motivos para nos preocupar, pois em pleno século XXI, essa cena é recorrente. De um lado, o professor que ensina sempre do mesmo jeito; de outro, o aluno que dificilmente tem interesse em aprender de forma repetitiva. Os diálogos acima denunciam a precária situação que insiste em perpetuar em torno do ensino de ciências, em particular, no ensino de Física.

De acordo com Xavier (2005), os alunos chegam ao Ensino Médio, traumatizados pela "ciência" do Ensino Fundamental. Muitos vêm com a ideia de que a física é algo impossível de se aprender e não verificam que é uma ciência experimental e de grande aplicação no dia a dia. Na perspectiva de Sousa (2002), os autores dos livros ainda enfatizam o vestibular como forma de mostrar a preocupação com o futuro do aluno. Esta tendência em direcionar o ensino de Física para a resolução de problemas que, geralmente, contem inúmeros cálculos fortemente influenciados pelo uso do livro didático, é alvo de críticas às editoras e também aos autores dos livros (ROSA, 2005).

ENSINO TRADICIONAL E quem você responsabiliza por isso?

FÍSICA NOVA: Não há uma causa única, mas você, Ensino Tradicional, poderia pelo menos deixar de ser tão inflexível com as mudanças que precisam acontecer.

ENSINO TRADICIONAL: Não vou carregar essa culpa sozinho. Infelizmente, em pleno século XXI, a Física ainda é apresentada no Ensino Médio de forma desarticulada. E entre tantos fatores que geram uma aprendizagem deficiente, está a inabilidade do professor em estabelecer relações dos saberes com a realidade do aluno.

FÍSICA NOVA: E somado a isso, um Ensino Tradicional que, sozinho, não atinge os objetivos requeridos pelos documentos que norteiam o ensino de Ciências da Natureza. E assim, essa prática impede que o aluno desenvolva suas capacidades de pensar e refletir sobre a linguagem científica, tão presente no seu cotidiano. As pesquisas de Neto e Pacheco (apud NARDI, 1998), relacionadas ao ensino de física, demonstram que esse tem privilegiado a preparação para resolução de exercícios de vestibular e objetivam pela memorização e soluções algébricas, quando o espírito investigativo e criativo deveria estar atrelado ao processo de ensino. 
ENSINO TRADICIONAL: Mas Física Nova, os alunos precisam resolver muitas questões para aprender, são muitas fórmulas, e por isso, a memorização e a repetição são necessárias! Além disso, o próprio Bonadiman (2003) destaca em um trecho de seu trabalho, a dificuldade gerada pela resistência dos alunos, quando o assunto é mudança.

FÍSICA NOVA: Fórmula são necessárias e importantes, mas não contribuem sozinhas para uma aprendizagem significativa. Além disso, segundo Galiazzi e Gonçalves (2004) a maneira como um professor desenvolve um assunto em sala de aula, em muito influencia o educando a gostar ou não do que está sendo tratado. As dificuldades que o professor enfrenta em sala de aula principalmente, aquelas relacionadas com questões do interesse e da motivação dos alunos, podem ser superadas por eles por meio de uma metodologia de ensino que seja adequada à realidade do aprendiz.

ENSINO TRADICIONAL: Invenções. Utopias e teorias que nunca funcionam. Ele precisa saber o conteúdo mínimo, o básico de cada assunto da física, e isso basta.

FÍSICA NOVA: E a criatividade e a imaginação dos alunos, onde ficam?

ENSINO TRADICIONAL: (Rsrsrs)... ficam para as aulas de artes!

FÍSICA NOVA: Agora, chegou você no ponto aonde eu queria. Imaginação e criatividade são essenciais a todas as disciplinas e, principalmente, ao aprendizado.

ENSINO TRADICIONAL: E qual é a sua proposta, Física Nova, a salvadora da educação!

FÍSICA NOVA: Não quero salvar nada, apenas tentar fazer diferente, pois o ensino como está, repleto de definições a serem decoradas e exercícios a serem resolvidos, tem fracassado. Tenho pensado em abordar conteúdos da Física Moderna, como a Relatividade Restrita ou Especial de Einstein, a partir do conceito de movimento relativo, nas turmas do $1^{\circ}$ ano, e inserir o teatro como uma prática educativa dentro da escola.

ENSINO TRADICIONAL: Isso não é nada inédito, muito menos a fórmula ideal.

FÍSICA NOVA: Mas não busco ineditismos nem fórmulas ideias. "Ideal", na minha concepção, é agregar todas as alternativas didáticas que mantenham o interesse do aluno em aprender, contribuindo assim para a melhoria do seu aprendizado, onde o eixo do ensino deixa de ser "o que ensinar" e passa a ser "para que ensinar". E o teatro é uma delas.

ENSINO TRADICIONAL: Agora, começou a bagunçar as ideias. Primeiro fala de mudanças, depois de juntar a ciência com as artes?

FÍSICA NOVA: Isso mesmo! Ensinar conteúdos de física através do teatro! E já comecei a mexer meus pauzinhos...

ENSINO TRADICIONAL: E que relação pode haver entre arte e ciência?

FÍSICA NOVA: Posso começar a te responder isso usando as ideias de Ferreira (2010) que nos diz que para aproximarmos a arte e a ciência, faz-se necessário conhecermos cada um desses 
campos e, a partir disso, buscarmos outra dimensão do pensamento que possa identificar os pontos divergentes, encontrar pontos convergentes, trazer à tona o que está por trás de cada discurso, de cada método ou teoria, de modo a conhecer melhor esses campos, entendê-los e poder assim articulá-los.

ENSINO TRADICIONAL: Certo. Ok, mas dê então um exemplo desses pontos convergentes. FÍSICA NOVA: Existe vários exemplo como o defendido por Moreira (2012) para quem essa convergência decorre do fato de que elas estão ligadas à mesma busca imaginativa humana, embora pertencentes a domínios diferentes de conhecimento. As aproximações entre arte e ciência, portanto, revelam-se muito ricas se olhadas dentro de um mesmo sentimento do mundo. A criatividade e a imaginação são o húmus comum de que se nutrem. Há ainda a visão de Rojo (2011) em cujos territórios da imaginação, a literatura e ciência, por exemplo, compartilham uma fronteira indiscernível, talvez porque definitivamente, toda linguagem seja metafórica.

É muito interessante como Zanetic (2006) nos diz que as ciências podem muito bem atuarem como instrumentos úteis, tanto para o pensador diurno, dominado pelo discurso racional, e para o pensador noturno, marcado pelo pensamento imaginário e sonhador. A grande ciência, nos seus momentos criativos de ruptura, nasce do encontro dessas duas vertentes. Precisamos construir a ponte entre essas duas culturas.

ENSINO TRADICIONAL: Muito bonito tudo isso, mas e daí? E o teatro, onde entra? Você falou de imaginação e criação como pontos de convergência entre a arte e a ciência. Falou sobre o ensino, seus problemas e propostas. E qual a relação disso tudo com o teatro científico e a tal da relatividade.

\section{O Teatro e a Relatividade}

[A conversa continua...]

FÍSICA NOVA: De acordo com Oliveira \& Zanetic (2004) o teatro, ao trabalhar a sensibilidade, a percepção, a intuição e as emoções pode levar ao público uma maior aproximação dos conteúdos científicos, por meio de uma forma lúdica, permitindo que o espectador, e também quem atua na peça, possa fazer relações com questões sociais, políticas, religiosas e científicas, mostrando que esses aspectos se influenciam mutuamente.

ENSINO TRADICIONAL: Teatro Científico na escola como recurso de ensino e aprendizagem?

FISICA NOVA: Isso mesmo. Aluno sem motivação, não tem bom rendimento na escola. $\mathrm{O}$ teatro científico pode contribuir para disseminar a cultura científica. Veja o que diz, Montenegro et. al., (2005): "o teatro tem todas as potencialidades para ser encarado como um veículo transmissor de conceitos científicos através do qual a aprendizagem é feita de forma 
simples, lúcida e agradável. Para, além disso, o teatro, se levado a cabo nas escolas, possibilita o desenvolvimento pessoal, permite ampliar o espírito crítico e o exercício da cidadania".

ENSINO TRADICIONAL: E quais temas pretende abordar junto com essa novidade de teatro científico?

FISICA NOVA: Tópicos de Física Moderna, inicialmente, a Relatividade Restrita de Einstein.

ENSINO TRADICIONAL: Mas por que a Física Moderna?

FISICA NOVA: Muitos autores defendem a introdução da Física Moderna e Contemporânea (FMC) no ensino médio. Dentre as justificativas está: a que facilita a aprendizagem subsequente da FMC; a possibilidade dos estudantes desenvolverem um entusiasmo mais duradouro pela ciência; a necessidade de que a FMC seja tratada como um elemento cultural. Com o intento de que toda a Física faça parte da formação cultural dos estudantes, Carvalho e Zanetic (2004) defendem que a introdução da FMC na educação básica deverá ocorrer em articulação com a arte. Dentre as possibilidades, o ensino de Física, articulado com várias áreas do conhecimento, favoreceria uma educação "problematizadora" e em sintonia com questões sociais mais amplas (ZANETIC, 2005).

ENSINO TRADICIONAL: Mas agora voltando à sua ideia de usar o teatro científico, me responda: quais autores tem lhe dado respaldo pra desenvolver esse trabalho?

FÍSICA NOVA: Nessa nossa conversa já lhe falei de alguns. Mas essa pesquisa, de uma forma geral, tem como fundamento teórico principal, autores que tem contribuído com suas experiências educacionais na conscientização de se utilizar esse mecanismo didático para assim obter resultados mais concretos na educação. São eles Olga Reverbel (1993), Ingrid Koudela (1992) e José Antônio Dominguez (1978) e Zanetic (2004).

ENSINO TRADICIONAL: Nenhum desses nomes me é familiar...

FÍSICA NOVA: Ah, e objetivando complementar essa proposta de inovação utilizo as ideia de Vygotsky a respeito da relação entre desenvolvimento humano e arte.

ENSINO TRADICIONAL: Esse nome é conhecido. Estou interessado em saber mais sobre o que esses autores têm a dizer sobre essa "viagem" de teatro na Educação.

FÍSICA NOVA: Talvez, lhe apresentando as ideias desses autores, eu consiga persuadi-lo a rever seus conceitos sobre o ensino de Física.

Reverbel (1989) esclarece que a expressão surge com a vida, desde o nascimento do bebê, por meio de experimentações e de reações naturais. E, com seu crescimento, há o desenvolvimento de tais manifestações conforme as mudanças do meio social e da aprendizagem oral, visual e sonora. Mais tarde, ao ingressar na escola, "as manifestações expressivas da criança são percebidas e orientadas pelo professor, a quem cabe acompanhar e orientar as mudanças de comportamento do aluno, estimulando seu desenvolvimento cognitivo, psicomotor e afetivo" (REVERBEL, 1989). 
Dominguez (1978, p. 21) leva em conta que, ao se trabalhar com teatro na escola, deve ter como objetivo levar os alunos a desenvolver características primordiais para um bom desempenho escolar, como: espontaneidade, aceitação de regras, criatividade, autoconhecimento, senso-crítico, raciocínio-lógico, intuição, conhecimento do grupo e de si próprio e do conhecimento do ambiente.

Da mesma forma que Reverbel (1989), o autor supracitado alerta para a dificuldade de se trabalhar com essa técnica, sugerindo que, para atingir tais objetivos, o professor que se propor a trabalhar com teatro, deve procurar desenvolver suas atividades de maneira que os alunos sintam-se sempre motivados, impondo disciplina, mas sem exageros e deixando-os livres para despertar o "ator" que há dentro de cada um.

Para Dominguez (1978, p. 21), o professor ao trabalhar o teatro na escola, deve mediar as tarefas, levando os alunos a serem líderes, auxiliando-os a resolver conflitos que ainda não sabem superar, na medida em que forem surgindo. Segundo ele, "onde o professor se torna indispensável é justamente em clarear, em levantar, em resolver as barreiras emocionais que o grupo encontra e que impedem que o trabalho se desenvolva de forma harmônica".

O professor deve atentar para que a atividade teatral não centralize somente na montagem de peças, mas que o principal foco seja na formação do indivíduo, pois de acordo com Koudela (1992), "o foco passa a ser o desenvolvimento da criança ou do jovem e a livre expressão de sua imaginação criativa".

Koudela (1992) ressalta em seus trabalhos que antes da atuação no palco, devem ser trabalhados os jogos teatrais ou jogos improvisacionais, com o intuito de iniciá-lo na prática teatral. O sistema de jogos teatrais desenvolvido pela Diretora, atriz e professor de Teatro, Viola Spolin, foi exposto pela primeira vez, em 1962, em seu livro "Improvisação para o Teatro". Esses jogos abordam improvisações teatrais cerceadas por regras, entre as quais se destacam o acordo grupal, o foco, a instrução e a avaliação. A autora parte do princípio de que todas as pessoas podem atuar no palco porque todos são capazes de improvisar.

ENSINO TRADICIONAL: E quanto a Vygotsky, o que ele tinha a dizer sobre teatro e educação? E a grande novidade que queria me contar?

Japiassu (1999) apresenta um estudo, onde é abordada a relação de Vygotsky com o teatro de vanguarda russo-soviético e Barros (2011) mostra alguns resultados de um trabalho que investiga as profundas relações dos escritos de Vygotsky com a arte teatral, arte que já de longo tempo vem sendo utilizada como estratégia de ensino nas escolas brasileiras e que para a literatura (JAPIASSU, 1999; KOUDELA, 2010) é justificado pela dinâmica de ensino em agregar linguagens, conceitos, contextos, ações e sentimentos, oportunizando a jovens aprendizes um conhecimento integrado com possibilidades de libertar a criatividade e expressividade do jovem. Para este autor, "a experiência artística é uma necessidade de todo ser humano" (VYGOTSKY, 2001).

A teoria sociointeracionista de Vygotsky destaca a interação entre grupos como instrumento de sistematização e apropriação do conhecimento científico. Vygotsky considera a arte importante 
para o desenvolvimento humano e o teatro científico se harmoniza com essas ideias na medida em que permite troca de experiências entre os alunos, e destes com o professor, além de oportunizar, através da arte, novas leituras acerca dos conteúdos de Física. Teatralizar o conhecimento científico incentiva nos alunos o desenvolvimento da criatividade na criação de uma peça, pois eles, mediados pelo educador, irão propor ideias e diálogos a serem vivenciados na encenação desse conhecimento.

ENSINO TRADICIONAL: Estou começando a entender porque você escolheu as ideias de Vygotsky para ajudar no seu trabalho e diversificar as aulas de Física.

FÍSICA NOVA: Interação social, mediação, desenvolvimento humano e as artes, mudança de visão e postura do educando e educador, são aspectos que colaboram com a aprendizagem.

ENSINO TRADICIONAL: É, parece fazer sentido. E se existe fundamentação para isso, quem sou eu pra discordar...

FÍSICA NOVA: Isso é sinal de que a sua mente está evoluindo, meu caro, Ensino Tradicional. ENSINO TRADICIONAL: E que novidade é essa, de levar as ideias de Einstein, sobre a Relatividade, surgidas há mais de 100 anos, para a sala de aula?

FÍSICA NOVA: De uma forma geral, posso justificar a escolha diante da riqueza de possibilidades que a Relatividade pode se apresentar aos olhos do estudante. Raramente, os alunos estudam Física Moderna no Ensino Médio e a Relatividade pode ser abordada a partir de vários contextos além de ter provocado grandes mudanças na forma de ser e pensar do homem, e ter permitido a tecnologia que hoje está à nossa disposição!

ENSINO TRADICIONAL: E por que escolheu Einstein e a Relatividade?

FÍSICA NOVA: Einstein, além de ter sido um físico teórico brilhante em suas considerações foi além: ele estudou muito sobre filosofia e foi um homem preocupado com questões sociais, como a perseguição do povo judeu e sua campanha antiarmamentista. Mas também foi um homem passível de erros, assim como a ciência. O aluno deve entender isso.

ENSINO TRADICIONAL: Então ele foi um pacifista?

FÍSICA NOVA: Foi sim.

ENSINO TRADICIONAL: Não conhecia esse lado humano do cientista...

FÍSICA NOVA: Então, podemos explorar tanto os aspectos científicos e históricos, quanto também o lado humano de Einstein.

ENSINO TRADICIONAL: E a Relatividade?

FÍSICA NOVA: A Relatividade não foi só um amontoado de ideias, mas permitiu questionamentos sobre rigidez do tempo e do espaço, estabelecida pela mecânica Newtoniana. Colocou também em questão outros conceitos bem estabelecidos pela Física Clássica, como a gravidade, 
antes uma força agindo à distância, e agora, interpretada como a curvatura do espaço causada pela presença de uma massa.

ENSINO TRADICIONAL: E a Relatividade foi tudo isso?

FÍSICA NOVA: Ah, e além dos aspectos científicos e históricos, ela também teve consequências na tecnologia do GPS. Os alunos sabem nada ou quase nada sobre Einstein e o que ele fez de fato.

ENSINO TRADICIONAL: E foi somente uma abordagem conceitual?

FISICA NOVA: Além de trabalhar conceitos como referencial inercial, movimento relativo, os alunos puderam compartilhar das visões de Galileu e Einstein sobre tempo e espaço quando analisados sobre diferentes referenciais. A Relatividade também pode ser explorada historicamente, pois a partir das conclusões de Einstein, apoiadas em posições já existentes de outros cientistas, de que a massa multiplicada pela velocidade da luz ao quadrado pode se converter em grandes quantidades de energia, permitiu posteriormente, a geração de energia nuclear e foi, também, o estopim para se fabricar as temidas bombas nucleares, preocupação exposta pelo próprio cientista na famosa carta enviada ao presidente dos Estados Unidos, Franklin Roosevelt.

ENSINO TRADICIONAL: Hum... quer dizer que o conceito de massa, tomado, também, como imutável sob a visão Newtoniana, foi levado ao entendimento dos alunos dentro de um contexto histórico?

FISICA NOVA: Sim. E isso levou o estudante a conhecer um pouco da história da bomba atômica e de uma das equações mais famosas da Física. Motivou o aluno a querer saber se a Relatividade Restrita permitiu alguma aplicação tecnológica.

ENSINO TRADICIONAL: Aí é onde entra o GPS...

FISICA NOVA: Isso mesmo! Consegui fazer uma aproximação entre o GPS e a Relatividade. Pois sem as correções relativísticas, as localizações de pontos na superfície da Terra seriam precárias. Expliquei que é a calibragem dos satélites do GPS, que orientam aviões e navios. Pois a velocidade de $14 \mathrm{mil} \mathrm{km} / \mathrm{h}$ dos satélites faz seus relógios internos atrasarem alguns milionésimos de segundo por dia em relação aos relógios da Terra.

ENSINO TRADICIONAL: E por que se usa o termo "restrita" ou "especial"?

FISICA NOVA: O termo é usado porque ela é um caso especial do princípio da relatividade onde os efeitos da gravidade são ignorados. Dez anos após publicar a teoria especial, Einstein lançou a teoria geral da relatividade, que é a versão especial, mas agora, considerou os efeitos da gravidade.

ENSINO TRADICIONAL: E o que diz os postulados da relatividade?

FISICA NOVA: O primeiro postulado diz que as leis que regem um sistema físico são as mesmas em qualquer sistema de coordenadas inerciais. Ou seja, não importa se você está parado 
dentro de um navio que segue em movimento uniforme ou está parado em terra firme; as leis físicas que governam as mudanças de estado permanecem iguais.

ENSINO TRADICIONAL: E qual é o postulado que fala sobre a constância da velocidade da luz?

FISICA NOVA: É o segundo. Ele diz que a luz, no vácuo, tem a mesma velocidade c em qualquer sistema de coordenadas inercial.

ENSINO TRADICIONAL: Deixa ver se entendi: a velocidade da luz no vácuo é igual para todo observador e não depende da fonte que está emitindo a luz nem tampouco do observador que faz a medição.

FISICA NOVA: Correto, meu caro.

ENSINO TARDICIONAL: O primeiro postulado é mais fácil de ser aceito... já o segundo, não parece tão óbvio.

FISICA NOVA: Os alunos realmente acham estranho quando se fala sobre isso.

ENSINO TRADICIONAL: Quer dizer que o aluno aceita a ideia, mas não compreende com clareza?

FISICA NOVA: Mais ou menos. No entanto, se o professor tiver paciência e boa vontade, pode demonstrar o segundo postulado através das transformações de Lorentz. Não é coisa de outro mundo.

ENSINO TRADICIONAL: Lorentz... deve ser outro nome que colaborou indiretamente com a Relatividade de Einstein, estou certo?

FISICA NOVA: Perfeitamente.

ENSINO TRADICIONAL: E quais as consequências dessa teoria?

FISICA NOVA: A Relatividade restrita ou especial tem consequências consideradas bizarras.

ENSINO TRADICIONAL: Por quê?

FISICA NOVA: Porque estas consequências estão relacionadas a comparação entre observadores que se movimentam a velocidades próximas à da luz.

ENSINO TRADICIONAL: Ah, essa é a consequência que o tempo apresenta com a teoria: o tempo, assim como o movimento passa a ser relativo e vai depender de um referencial. É a dilatação temporal!

FISICA NOVA: "Eventos que ocorrem simultaneamente em um referencial, não são simultâneos em outro referencial em movimento relativo".

ENSINO TRADICIONAL: É a falta de simultaneidade... 
FISICA NOVA: E a última: “As dimensões de objetos medidos em um referencial podem ser diferentes para outro observador em outro referencial em movimento". Se um corpo está em movimento ao longo de um eixo, a dimensão do corpo ao longo deste eixo parecerá menor do que quando o mesmo corpo estiver parado em relação ao referencial do observador. Será que pode me dizer qual é esta consequência, meu caro?

ENSINO TRADICIONAL: É a contração dos comprimentos!

FISICA NOVA: Muito bem.

ENSINO TRADICIONAL: Pois me diga, que aspectos foram trabalhados juntos com a atividade teatral?

FÍSICA NOVA: Os alunos foram estimulados a fazerem muita pesquisa e leitura.

ENSINO TRADICIONAL: E pesquisa e leitura são consideradas processos de aprendizagem? FÍSICA NOVA: Com certeza. Para Gomes et al. (2011) a pesquisa pode mobilizar processos cognitivas em que não se faz apenas por meio de aulas expositivas. Ele diz que:

[...] um ensino com pesquisa é capaz de mobilizar várias aprendizagens no estudante, como sua capacidade de levantar hipótese, checá-las, comprová-las, reformulá-las e tirar conclusões para posteriormente comunicá-las. Tais aprendizagens, além de mobilizar a memória, permitem ao estudante a mobilização de outros processos cognitivos como sua capacidade de pensar e expressar seu pensamento por meio da linguagem (GOMES et al., 2011 p. 12).

ENSINO TRADICIONAL: Interessante... bom, agora vamos ao que mais interessa: conte sobre a peça.

FÍSICA NOVA: Está curioso, hein? Pois, vamos lá!

\section{Estratégias utilizadas e produto gerado}

[A Física Nova mostra ao Ensino Tradicional, todas as etapas trilhadas, as estratégias usadas e por fim, o produto gerado]

FÍSICA NOVA: A primeira parte do trabalho foi iniciada em maio de 2014 e a conclusão aconteceu no mês de novembro com a estreia da peça sobre recortes da vida do cientista, intitulada "EINSTEIN". A peça era composta de quatro cenas intercaladas pela fala de duas narradoras (alunas):

CENA 1: Nascimento

CENA 2: Infância e a bússola

CENA 3: Jovem recém - formado e sem fama 
CENA 4: Professor consagrado e judeu

A última cena apresentou um aspecto histórico de profundas transformações para o mundo: os nazistas tomam o poder na Alemanha em 1933. Os alunos compreenderam pelas leituras e discussões que Einstein não foi somente um cientista de "grandes experimentos imaginário", mas vivenciou um período histórico e social importante e com profundas implicações filosóficas e científicas para as gerações futuras.

A segunda parte iniciou no mês de março de 2015 com a participação de novos alunos do $1^{\circ}$ Ano, do turno da manhã, que se mostraram bastantes interessados para conhecer sobre Einstein e sua Teoria da Relatividade. Eles realizaram pesquisas, fizeram leituras e assistiram a diversos vídeos sobre Albert Einstein e sua Teoria da Relatividade. Alguns dos novos integrantes gostavam muito de ler e de participar das discussões. A Relatividade Espacial foi abordada junto com a cinemática e foi realizado um breve paralelo da Relatividade de Galileu versus a Relatividade de Einstein, a partir da composição da velocidade.

Além de falar sobre as visões de Galileu, Newton e Einstein sobre o movimento, foram discutidas questões sobre a velocidade da luz e suas implicações no tempo e no espaço. Os alunos lembravam-se da figura de Einstein como um maluco que fez algo importante, mas não sabiam o quê e não tinham nenhuma ideia sobre a Relatividade.

Vejamos alguns comentários:

"Eu já vi uma foto dele dando a língua, mas não sei nada sobre ele". (Aluna 01);

"Acho que ele fez alguma coisa importante, mas não sei o que foi”. (Aluna 02).

Tínhamos muito trabalho pela frente, por isso, tive que dividir essa nova experiência dos alunos em duas etapas:

$\underline{\mathbf{1}^{\mathbf{a}} \text { Parte: }}$ Conhecer, através de pesquisas em livros, internet e documentários, a história de Albert Einstein para posteriores discussões e, finalmente, pensar na criação e montagem da peça. Os alunos contaram com o apoio e colaboração do diretor do Núcleo de Artes do município, Leandro Gomes. Ele cursa teatro na Universidade Regional do Cariri e auxiliou os ensaios, no anfiteatro do município.

$\underline{\mathbf{2}^{\mathbf{a}} \text { Parte: }}$ Compreender, através de pesquisas, leituras e vídeos, sobre as ideias da Relatividade Especial, para enfim teatralizar este conhecimento.

Os alunos deram asas a criatividade e a imaginação na criação dos diálogos, muitas vezes adormecidas, por causa de métodos e professores despreparados. Ao acompanhar as discussões que levaram a construção das peças, foi notada a capacidade dos alunos em transformar as ideias da Relatividade Especial em trama teatral, sendo assim, além da atenção e motivação dos alunos, foi incitada também a capacidade no ato de pensar.

O enredo da segunda peça "VIAGEM AO ESPAÇO NA VELOCIDADE DA LUZ: UMA FRAUDE" aborda questões como a ética e a vaidade humana. Nesse enredo, uma médica falsa engana uma velhinha com uma ilusória viagem ao espaço para recuperar o viço e a juventude. 
O tempo relativizado, à velocidade da luz, proposto por Einstein na Relatividade Especial, é o ingrediente científico que concede vida à peça. Foi observado, na criação e montagem das peças, que ao exercitar a imaginação, propondo enredos e diálogos, ao teatralizar o conhecimento adquirido, o estudante além de mobilizar o aspecto cognitivo, vivenciou através da interação e mediação aluno-aluno e aluno-professor, a socialização e a afetividade ao compartilhar saberes e experiências verbalizadas através de várias linguagens, emoções e sentimentos.

ENSINO TRADICIONAL: Ao que me parece, você conseguiu despertar em alguns alunos o gosto pela arte teatral e também pela física.

FÍSICA NOVA: Acredito que sim. Em longo prazo, teremos resultados maiores e melhores, porque não pretendo parar por aqui.

ENSINO TRADICIONAL: Depois de fazer uma auto - reflexão, percebo que sozinho não consigo mobilizar os aspectos cognitivos relacionados com a aprendizagem e com o desenvolvimento do estudante.

FÍSICA NOVA: Veja bem, não é que você seja tão ruim, mas é interessante trabalhar novas abordagens, utilizar recursos que possam te auxiliar melhor, tornar o ensino mais dinâmico e agradável.

ENSINO TRADICIONAL: Vejo também que o seu trabalho gerou um produto de inovação dentro da escola: UM GRUPO DE TEATRO!

FÍSICA NOVA: É isso mesmo! E tem um nome: GRUPO DE TEATRO CIENTÍFICO "FÍSICA COM ARTE". Tem até um site...

ENSINO TRADICIONAL: Verdade? E quem criou este site?

FÍSICA NOVA: Os alunos participantes. Lá eles contam como tudo começou. Disponibilizaram os livros e vídeos utilizados durante as aulas sobre Einstein e sobre a Relatividade Especial. Também estão disponíveis para os visitantes, as peças e uma música feita por eles. Lá eu ainda justifico o porquê de trabalhar atividades artísticas como o teatro e, também, porque abordar conteúdos de Física Moderna na $1^{\mathrm{a}}$ série do Ensino Médio.

ENSINO TRADICIONAL: Muito bom!

FÍSICA NOVA: É, mas a luta deve continuar...

ENSINO TRADICIONAL: Quero visitar este site, qual é o endereço virtual?

FÍSICA NOVA: Que bom que o sensibilizei. Creio que nossa grande tarefa como professor é buscar formas de tornar o ensino mais sincero e prazeroso. Isso não é fácil... ah, o endereço do site é: www.artecomfisica.wix.com/física-com-arte.

ENSINO TRADICIONAL: Pela sua experiência, percebi que atividades artísticas envolvem a interação social e são parte da cultura humana, uma vez que permitem mobilizar aspectos 
cognitivos, afetivos e sociais, pois estes tem implicações importantes no processo de aprendizagem.

FÍSICA NOVA: E agora, somos parceiros de verdade?

ENSINO TRADICIONAL: Tenho certeza que sim. Conte sempre comigo, porque a partir de agora, também contarei com você para me modificar. De hoje em diante, quero uma escola que ofereça várias perspectivas para aprender e ensinar!

FÍSICA NOVA: Pois vamos lá! Mãos à obra, que nosso trabalho está só começando...

\section{Epílogo}

Essa história parece ter terminado muito bem, depois de muito esforço de convencimento e argumento da Física Nova. Contudo, bem sabemos que no dia a dia das escolas, nem sempre essa história acabará bem. O ensino hoje, em todas as suas esferas, é tomado por um forte tradicionalismo que muitas vezes impede a realização de atividade que verdadeiramente podem e desejam inovar o ensino.

Professores que aceitam esse desafio, como a Física Nova aceitou, devem estar bem cientes dos riscos e das dificuldades, e não devem se deixar abater nem se limitar por eles. Mas aqui não tratamos de um manual de autoajuda para o ensino de física. Aqui foi apresentada uma proposta que, como todas as outras, possuiu falhas e equívocos, resultados positivos e outros nem tanto; receios, incertezas, momentos de sucesso e insucesso; alunos que apoiam e alunos que desdenham. E é com todas essas dualidades que se constrói nas escolas um projeto de inovação para o Ensino de Física.

\section{Referências bibliográficas}

BARROS, E. R. O. Entre Linguagens e Pensamentos: Vigotsky e o Teatro. Trabalho de Conclusão de Curso, UNIVERSIDADE FEDERAL DE GOIÁS, 2011.

BONADIMAN, H.; NONENMACHER, S. E. B. Uma concepção metodológica para o ensino de Física. Departamento de Física, Estatística e Matemática. Universidade Regional do Noroeste do Estado do Rio Grande do Sul, 2003.

BRASIL, MEC, Secretaria de Educação Média e Tecnológica. Parâmetros Curriculares Nacionais para o Ensino Médio, Conhecimento de Física. Brasília, 1999.

DOMINGUEZ, J. A. Teatro e Educação: Uma Pesquisa. Rio de Janeiro: Serviço Nacional do Teatro, 1978. p. 21.

. Lei de Diretrizes e Bases da Educação Nacional, Lei nº 9.394, de 20 de dezembro de 1996. 
. Parâmetros Curriculares Nacionais (Ensino Médio): Parte III Ciências da Natureza, Matemática e suas Tecnologias. Brasília: Ministério da Educação e Cultura, 2000.

. PCN+: Orientações educacionais complementares aos Parâmetros Curriculares Nacionais, Ciências da Natureza, Matemática e suas Tecnologias. Brasília: Ministério da Educação e Cultura, 2002.

FERREIRA, F. C. Diálogos sobre o tempo: arte e ciência, Educação. 2004. Tese (Doutorado) - Universidade de São Paulo, São Paulo, SP, Brasil.

GALIAZZI, M. C; GONÇALVES, F. P. A natureza das atividades experimentais no ensino de ciências: Um programa de pesquisa educativa nos Cursos de Licenciatura. In: MORAES, R.; (ORGS). Educação em Ciências. Ijuí: Unijuí, 2004. p. 237-252.

GOMES, R. C. S.; FIGUEIREDO, A. M. R., GHEDEIN, E. Os processos Cognitivos Mobilizados pelo Ensino com Pesquisa na Pedagogia Universitária. 2011.

HAUSER, A. História Social da Literatura e da Arte. São Paulo: Mestre Jou, 1972.

JAPIASSU, R. O. V. As artes e o desenvolvimento cultural do ser humano. Educação \& Sociedade, ano XX, n. 69, p. 34-59, 1999.

JAPIASSU, R. O. V. Jogos Teatrais na Escola Pública. Revista Faculdade de Educação, v. 24, São Paulo, 1998.

KOUDELA, I. D. Apresentação do Dossiê Jogos Teatrais no Brasil: 30 anos - Fênix - Revista de História e Estudos Culturais. Janeiro/ Fevereiro/ Março/ Abril. 2010.

KOUDELA, I. D. Jogos teatrais. São Paulo: Perspectiva, 1992.

PIETROCOLA, M. Curiosidade e imaginação: os caminhos do conhecimento nas ciências, nas artes e no ensino. In: CARVALHO, A. M. P. (Ed.). Inovação no Ensino de Ciências. São Paulo: Thomson, 2004.

Linguagem e estruturação do pensamento na ciência e no ensino de ciências. In:

PIETROCOLA, M. (Org.). Filosofia, Ciência e História. 1. ed. São Paulo: Discurso editorial, 2005.

; POGIBIN, A.; ANDRADE, R. de, ROMERO, T. R. Física em contextos: pessoal, social e histórico. São Paulo: FTD, 2011.

MIZUKAMI, M. G. N. Ensino: as abordagens do processo. São Paulo: EPU, 1986.

MONTENEGRO, B.; FREITAS, A. L. P.; MAGAlhãeS, P. J. C.; SANTOS, A. A.; VAlE, M. R. O papel do teatro na divulgação científica: a experiência da Seara da Ciência. Ciência e Cultura, v. 57, n. 4, p. 31-32, 2005. 
MOREIRA, M. A. Teorias de Aprendizagem. EPU. 2. ed. São Paulo, 2011.

MOREIRA, M. A. Tópicos em Ensino de Ciências. Instituto de Física, UFRGS, 1981.

OLIVEIRA, N. R.; ZANETIC, J. A presença do teatro no Ensino de Física. In: ENCONTRO NACIONAL DE PESQUISA EM ENSINO DE FÍSICA, XI, 2004. Atas...

OLIVEIRA, N. R., ZANETIC, J. A presença do teatro no ensino de física. In: ENCONTRO NACIONAL DE PESQUISA EM ENSINO DE FÍSICA, IX, 2004, Jaboticatubas, MG. Atas...

REVERBEL, O. G. Jogos Teatrais na Escola: Atividades de Expressões. Rio de Janeiro: Scipione, 1989.

REVERBEL, O. O Texto no Palco. Porto Alegre: Editora Kuarup, 1993.

REVERBEL, O. Um caminho do Teatro na Escola. São Paulo: Editora Scipione, 1989, p.24.

ROJO, A. Borges e a mecânica quântica. Campinas: Editora Unicamp, 2011.

ROSA, C. W. da; ROSA, A. B. Ensino de Física: Objetivos e imposições no Ensino Médio. Revista Electrónica de Enseñanza de lãs Ciencias, v. 4, 2005.

SARAIVA, C. C. Teatro Científico e Ensino de Química. 2007. Dissertação (Mestrado em Ensino de Química) - Faculdade de Ciências, Universidade do Porto, Porto.

SARAIVA-NEVES, M.; CABALLERO, C.; MOREIRA, M. A. Repensando o papel do trabalho experimental, na aprendizagem da Física em sala de aula: Um estudo exploratório. Investigações em Ensino de Ciências, v. 11, n. 3, p. 383-401, 2006.

SNOW, C. P. As duas culturas e uma grande leitura: Uma versão ampliada das duas culturas e a Revolução Científica. São Paulo: EDUSP, 1995.

VIEIRA, C. L. Einstein Reformulador do Universo. 2. ed. São Paulo: Odysseus Editora, 2003.

VYGOTSKY, L. S. Psicologia da Arte. São Paulo: Martins Fontes, 2001.

XAVIER, J. C. Ensino de Física: presente e futuro. In: SIMPÓSIO NACIONAL ENSINO DE FÍSICA, XV, 2005. Atas...

ZANETIC, J. Física também é cultura. São Paulo: Universidade de São Paulo, 1989.

Física e arte: uma ponte entre duas culturas. Pro-Posições, v. 17, n. 1, p. 39-57, jan./abr. 2006.

Física e cultura. Ciência e Cultura, São Paulo, v. 57, n. 3, p. 21-24, 2005. 
Física e literatura: construindo uma ponte entre as duas culturas. História, Ciências, Saúde, Manguinhos, v. 13 (suplemento), p. 55-70, 2006.

Literatura e cultura científica. In: ALMEIDA, M. J.; SILVA, H. C. (Eds.). Linguagens, leituras e ensino da ciência. Campinas: Mercado de Letras: Associação de Leitura do Brasil, 1998. 